蛇行するパンピー・トーラスの平衡と安定性

等々力二 郎

名古屋大学プラズマ研究所

( 1982 年 8 月 9 日受理 )

\title{
Equilibrium and Stability of Snake Bumpy Torus
}

\author{
Jiro Todoroki
}

(Received August 9, 1982)

\begin{abstract}
Equilibrium and stability of a toroidal closed-line configuration with finite $\ell= \pm 1$ distortion is investigated theoretically based on new ordering assumptions. A second order nonlinear differential equation describing equilibrium is derived, and its analytical solution is obtained for the parabolic pressure profile. As the plasma pressure increases, the cross section of the plasma column elongates to the vertical direction. The growth rate for $m=1$ displacement is given.
\end{abstract}

$\S 1$. 序 論

閉じた磁力線をもつ変形バンピー・トーラス（MBT)配位におけるプラズマのMH D平衡と 安定性が，以前の論文 ${ }^{[1,2]}$ で考察された。それらの理論では，もによってポロイダル方向の フーリエ成分を表わすととにすると， $\ell=0$ のバンピー磁場の成分と， $\ell= \pm 2$ の四重極磁場成 分は， $\ell= \pm 1$ 成分と共に有限の大きさをもつと仮定されている。その結果，プラズマの $\beta$ 值が

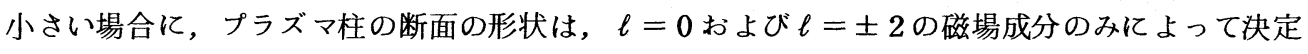
され，また， $\ell= \pm 1$ の磁場成分は, トーラスカとつり合ってトロイダル平衡を保つという役割 のみを荷っている。 $\ell= \pm 1$ 成分は， $\ell=0, \pm 2$ のそれと同じく有限の大きさと仮定されてい るにも拘らず，結果としては線形の効果しか現われていない。 ギャップ・シェルを用いたMB T実験 ${ }^{[3]}$ では, $\ell= \pm 1$ の磁場成分が, $\ell=0$ あるいは $\ell=$ 土2のそれにくらべてかなり大きな值をもつ場合があり，またての場合，以前の理論によって予 
測される程にはプラズマが不安定ではないように見える。それ故， $\ell= \pm 1$ 成分のもたらす高次 の影響を考虑するととが重要であると思われる。

ての論文では, $\ell= \pm 1$ の磁場成分が有限の大きさで, $\ell=0 ; \pm 2$ 等の磁場成分はそれに比 べて十分小さいような, 閉じた磁力線をもつ系のMH D平衡と安定性を考察する。との系での磁 力線の形を最低次で見れば，トーラス面内で左右に蛇行している。論文 $[1,2]$ における取扱い

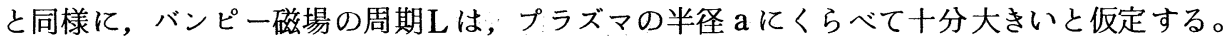
(Long-Thin 近似) すなわち，バンピーの波数を $\mathrm{h}=2 \pi / \mathrm{L}$ とするとき，ha は小さな パラメータとのオーダーであるとする。

次の節で, どのようなオーダリングを用いるのがよいか議論する。ミ3.では, $\ell= \pm 1$ の成分 が有限である場合のMHD平衡を記述する二階の非線形偏微分方程式を導き，§4で，エネルギ 一原理を簡単化して，一般的な安定条件について議論する。§5で, 圧力分布が半径の二乗に依 るような場合に対して，§3で導かれた非線形偏微分方程式の解析解を求め, またその $\mathrm{m}=1$ モ 一ドに対する不安定性の成長率を求める。

§2. オーダリング

どのようなオーダリングを用いるのが適当であるかを考えるのに， 円形断面の鋭い境界をもつ トーラス・テータ・ピンチのモデルによる計算の結果を見ておくのが有益である。一般に, 複数 個のフーリエ成分 $\ell$ の存在する場合には，プラズマ断面が円形であるという仮定はなり立たない から，それらの計算は正当性を失う。しかし，それらの中にもある種の物理的な効果が現われて いる。波数 $\ell$ をつたプラズマ表面の相対的変形度を $\delta \ell$ とするとき，大半径 $\mathrm{R} 。$ をもつトーラ スの平衡条件は $(\beta \ll 1$, ha $<1$ のとき)

$$
\mathrm{a} / \mathrm{R}_{0} \simeq \frac{1}{4}(\mathrm{ha})^{2} \delta_{1}\left(3 \delta_{0}+\delta_{2}\right)
$$

で与えられる ${ }^{[4]}$ 。また, $\mathrm{m}=1$ モードの成長率 $\gamma$ は, $\mathrm{v}_{\mathrm{A}}$ をアルフヴェン速度, bをプラズ マを囲む導体壁の半径とするとき，(やはり $\beta \ll 1, ~ h a<1$ として）

$$
\begin{aligned}
\left(\gamma / \mathrm{h} \mathrm{v}_{\mathrm{A}}\right)^{2} \approx & \frac{1}{4} \beta \delta_{1}^{2}\left[\left(2 \pm \frac{3}{2}\right)(\mathrm{h} \mathrm{a})^{2}-2 \beta(\mathrm{a} / \mathrm{b})^{2}\right] \\
& +\frac{1}{2} \beta\left[3 \delta_{0}^{2}+\delta_{2}^{2} \pm 4 \delta_{0} \delta_{2}\right]
\end{aligned}
$$


蛇行するバンピー・トーラスの平衡と安定性

となる ${ }^{[5]}$ これらの式をながめると, 次のオーダリングが示唆される。

$$
\delta_{1} \sim 1 ; \delta_{0} \sim \delta_{2} \sim \mathrm{ha} \sim \varepsilon ; \delta_{3} \sim \beta \sim \varepsilon^{2} ; \mathrm{a} / \mathrm{R}_{0} \sim \varepsilon^{3}
$$

以下において，我々は（1）のオーダリングを採用するととにする。しかし，可能なオーダリン グとしては,たとえば

$$
\delta_{1} \sim 1 ; \delta_{0} \sim \delta_{2} \sim \delta_{3} \sim \beta \sim \mathrm{ha} \sim \varepsilon ; \mathrm{a} / \mathrm{R}_{0} \sim \varepsilon^{3}
$$

のようなものが考えられる。（1）と（2）では， $\beta$ とha関係が異なる。（1）にくらべて (2) のオーダリングの方が, より $\beta$ のきな場合を取扱っていると考光る人もあるかも知れない。し かし，実際に計算を行ってみれば，（1）と（2）の相異は $\beta$ の大小にるのではなく， ha の大小 にあるととが判る。すなわち，（1）のオーダリングによると，（2）を用いたときよりも，バンピ 一磁場の波数について高次の効果を含めるてとができる。（1）を用いて得られる結果において， ( h a ) ${ }^{2}$ についての高次の項を落とすととによって，（2）を用いた結果を導き出すととができる。 （2）を用いたときには，展開の 2 次の項までの計算を行えばよいのに対し，（1）の場合には展開 を 3 次まで行う必要がある。

\section{§3. 平衡条件}

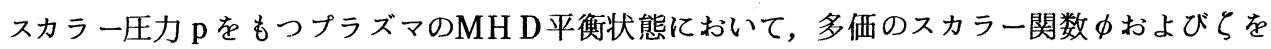

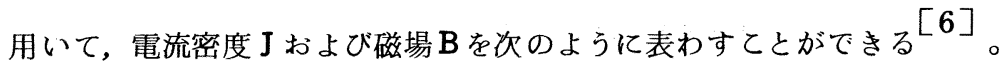

$$
\mathrm{J}=\boldsymbol{\nabla} \zeta \times \boldsymbol{\nabla}, \quad \mathrm{B}=\boldsymbol{\nabla} \phi+\zeta \boldsymbol{\nabla} \mathrm{p}
$$

このとき,プラズマの平衡条件は次のようになる。

$$
\text { B. } \nabla \mathrm{p}=0, \quad \text { B. } \nabla \zeta=1, \quad \operatorname{div} \mathrm{B}=0 \text {. }
$$

$\phi ， \zeta は$ 多価であるが，電流 J 及び磁場 Bが一価であるための条件として，トーラスを一周した ときの $\phi, \zeta$ の増加分 $[\phi],[\zeta]$ に対して, 次の関係が要請される。

$$
[\phi]=-\mathbf{I}(p), \quad[\zeta]=I^{\prime}(p) .
$$

$B \cdot \nabla \zeta=1$ の関係から得られる関係 


$$
[\zeta]=\oint \mathrm{d} \ell / \mathrm{B}
$$

を考虑すると，（4）のあとの条件は，よく知られた平衡の条件

$$
\mathrm{p}=\mathrm{p}(\oint \mathrm{d} \ell / \mathrm{B})
$$

そ他ならない。

トーラス座標 $(x, y, z)$ を円柱座標 $(\mathrm{R}, \Theta, Z$ ) と次の関係によって導入しょう。

$$
\mathrm{R}=\mathrm{R}_{0}-\mathrm{x}, \quad \mathrm{Z}=\mathrm{y}, \quad \Theta=\mathrm{z} / \mathrm{R}_{0} .
$$

そして, $\mathrm{z}=0, \pm \mathrm{L} / 2, \pm \mathrm{L} \cdots \cdots$...る各面に対して, 次のような鏡像対称性を仮定しよう ${ }^{[7]}$ すなわち，ベクトルBはてれらの各面についての鏡映に対して軸性べクトルとして振舞い, ベク トル J は極性ベクトルとして振舞うとする。ての鏡像対称性の結果として，あるトーラス領域内 に閉じとめられた磁力線は全て閉じているてとが保証される。てれらの対称性を，スカラー関数

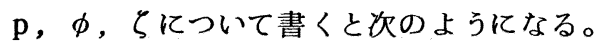

$$
\begin{aligned}
& p(x, y, z)=p(x, y, n L-z) \\
& \phi(x, y, z)-\phi\left(x, y, \frac{n L}{2}\right)=\phi\left(x, y, \frac{n}{2} L\right)-\phi(x, y, n L-z), \\
& \zeta(x, y, z)-\zeta\left(x, y, \frac{n}{2} L\right)=\zeta\left(x, y, \frac{n}{2} L\right)-\zeta(x, y, n L-z), \\
& \quad(n=0, \pm 1, \pm 2, \cdots \cdots)
\end{aligned}
$$

以下において，更に，y=z=0の面に対するもう一つの鏡像対称性，すなわち，p， yの偶関数であるとと，を仮定する（ての条件は容易に除くことができる。）

$\mathrm{x}, \mathrm{y}, \mathrm{z}$ 軸方向の単位ベクトルを，それぞれe $\mathrm{x}, \mathrm{e}_{\mathrm{y}}, \mathrm{e}_{\mathrm{z}}$ と書き，またべクトルの $\mathrm{x} \cdot \mathrm{y}$ 平面上への射影を添字上をつけて表わすととにする。オーダリング（1）の仮定の下で，演算子 $\nabla$ を

$$
\begin{aligned}
& \boldsymbol{\nabla}=\boldsymbol{\nabla}_{+}+\varepsilon \mathbf{e}_{z} \frac{\partial}{\partial z}+\varepsilon^{4} \mathbf{e}_{z} \frac{\mathrm{x}}{\mathrm{R}_{0}} \frac{\partial}{\partial z}+\cdots \cdots \\
& \boldsymbol{\nabla}_{+}=\mathbf{e}_{\mathrm{x}} \frac{\partial}{\partial \mathrm{x}}+\mathbf{e}_{\mathrm{y}} \frac{\partial}{\partial \mathrm{y}},
\end{aligned}
$$


とおき, 更に,

$$
\begin{aligned}
& \phi=\frac{1}{\varepsilon} \int_{0}^{z} \mathrm{~T}\left(\mathrm{z}^{\prime}, \mathrm{p}\right) \mathrm{d} z^{\prime}+\hat{\phi}-\mathrm{p} \hat{\zeta}, \\
& \zeta=\frac{1}{\varepsilon} \int_{0}^{z} \frac{\mathrm{d} z^{\prime}}{\mathrm{T}\left(\mathrm{z}^{\prime}, \mathrm{p}\right)}+\hat{\zeta}, \\
& T(z, p)=\left\{\left[\mathrm{B}_{0}+\varepsilon \mathrm{b}_{1}(z)\right]^{2}-2 \mathrm{p}\right\}^{1 / 2},
\end{aligned}
$$

とおく。Tはプラズマの反磁性電流の効果をとり入れたトロイダル磁場の軸上での值である。す ると，（4）は次のように書かれる。

$$
\begin{aligned}
& \mathrm{B}_{+} \cdot \nabla_{+} \mathrm{p}+\varepsilon \mathrm{B}_{\mathrm{z}} \frac{\partial \mathrm{p}}{\partial \mathrm{z}}=0, \\
& \mathrm{~B}_{+} \cdot \boldsymbol{\nabla}_{+} \hat{\zeta}+\varepsilon \mathrm{B}_{z} \frac{\partial \hat{\zeta}}{\partial z}=1-|\nabla z|^{2}-\varepsilon \frac{|\boldsymbol{\nabla z}|^{2}}{\mathrm{~T}}\left(\frac{\partial \hat{\phi}}{\partial z}-\mathrm{p} \frac{\partial \hat{\zeta}}{\partial z}\right), \\
& \nabla \cdot \mathrm{B}_{+}=-\varepsilon|\nabla \mathrm{z}|^{2} \frac{\partial}{\partial z}\left\{\mathrm{~T}+\varepsilon\left(\frac{\partial \hat{\phi}}{\partial z}-\mathrm{p} \frac{\partial \hat{\zeta}}{\partial z}\right)\right\}
\end{aligned}
$$

たぶし

$$
\begin{aligned}
& \mathrm{B}_{+}=\nabla_{+} \hat{\phi}-\mathrm{p} \boldsymbol{\nabla}_{+} \hat{\zeta}, \\
& \mathrm{B}_{\mathrm{z}}=|\boldsymbol{\nabla} \mathrm{z}|^{2}\left\{\mathrm{~T}+\varepsilon\left(\frac{\partial \hat{\phi}}{\partial \mathrm{z}}-\mathrm{p} \frac{\partial \hat{\zeta}}{\partial \mathrm{z}}\right)\right\},
\end{aligned}
$$

また $|\nabla z|^{2}=\left(1-\mathrm{x} / \mathrm{R}_{0}\right)^{-2}$ 。(9) （16）までの式で, $\partial / \partial \mathrm{z}$ のまえに形式的に $\varepsilon$ を 挿入してあるが，それを除けば，てれらの式は一般的に成り立つ式である。

さて, 関数 $\hat{\phi}, \hat{\zeta}, \mathrm{p}$

$$
\begin{aligned}
& \hat{\phi}=\varepsilon \hat{\phi}^{(1)}+\varepsilon^{2} \hat{\phi}^{(2)}+\cdots \cdots, \\
& \zeta=\varepsilon \hat{\zeta}^{(1)}+\varepsilon^{2} \hat{\zeta}^{(2)}+\cdots \cdots, \\
& p=\varepsilon^{2} \mathrm{p}^{(2)}+\cdots \cdots,
\end{aligned}
$$

と展開し, 最低次の磁力線の方程式が 


$$
\mathrm{x}=\mathrm{x}_{0}+\Delta^{\prime}(\mathrm{z}), \quad \mathrm{y}=\mathrm{y}_{0},
$$

で表わされるように，

$$
\hat{\phi}^{(1)}=\mathrm{B}_{0} \Delta^{\prime}(\mathrm{z}) \mathrm{x}
$$

とおく。(12)-(14) を順次 $\varepsilon$ の各オーダーについて解いていく。まず, $\mathrm{p}^{(2)}=\mathrm{p}^{(2)}\left(\mathrm{x}_{0}\right.$, $\left.\mathrm{y}_{0}\right)$ であり, $\check{\zeta}^{(1)}, \hat{\phi}{ }^{(2)}$ そついて

$$
\begin{aligned}
& \hat{\zeta}(1)=-\frac{\Delta^{\prime}}{\mathrm{B}_{0}} \mathrm{x}+\frac{1}{\mathrm{~B}_{0}} \int_{0}^{z}\left|\Delta^{\prime}\right|^{2} \mathrm{~d} z, \\
& \hat{\phi}^{(2)}=-\frac{\mathrm{b}_{1}^{\prime}}{4}\left(\mathrm{x}^{2}+\mathrm{y}^{2}\right)+\frac{\mathrm{g}_{2}(\mathrm{z})}{4}\left(\mathrm{x}^{2}-\mathrm{y}^{2}\right),
\end{aligned}
$$

となる。（20）において，(1)を考虑してある。（13）の $\varepsilon^{2}$ のオーダーの式から

$$
\begin{aligned}
\zeta^{(2)}= & -\frac{1}{\mathrm{~B}_{0}} \hat{\phi}^{(2)}+\frac{\mathrm{x}_{0}}{\mathrm{~B}_{0}}\left\{\int_{0}^{\mathrm{Z}}\left(-\frac{2}{\mathrm{R}_{0}}-\frac{3 \mathrm{~b}_{1}^{\prime}-\mathrm{g}_{2}}{\mathrm{~B}_{0}} \Delta^{\prime}\right) \mathrm{d} z+\frac{2 \mathrm{~b}_{1} \Delta^{\prime}}{\mathrm{B}_{0}}\right\} \\
& +\frac{1}{\mathrm{~B}_{0}} \int_{0}^{z}\left\{-\frac{2}{\mathrm{R}_{0}} \Delta-\frac{3 \mathrm{~b}_{1}^{\prime}-\mathrm{g}_{2}}{\mathrm{~B}_{0}} \Delta \Delta^{\prime}-\frac{3 \mathrm{~b}_{1}}{\mathrm{~B}_{0}}\left|\Delta^{\prime}\right|^{2}\right\} \mathrm{dz} \\
& +\frac{2 \mathrm{~b}_{1} \Delta \Delta^{\prime}}{\mathrm{B}_{0}},
\end{aligned}
$$

てれより，条件 (5) を考慮すると

$$
\frac{1}{\mathrm{R}_{0}}+\frac{1}{2 \mathrm{~L}} \int_{0}^{\mathrm{L}} \frac{3 \mathrm{~b}_{1}^{\prime}-\mathrm{g}_{2}}{\mathrm{~B}_{0}} \Delta^{\prime} \mathrm{d} \mathrm{z}=0 .
$$

なる条件が得られる。 $\hat{\phi}^{(3)}$ は次の式から决定される。

$$
\nabla_{+}^{2} \hat{\phi}^{(2)}=-\frac{2 \Delta^{\prime}}{\mathrm{B}_{0}} \frac{\partial \mathrm{p}^{(2)}}{\partial \mathrm{x}}-\mathrm{B}_{0} \Delta^{\prime \prime \prime} \mathrm{x} .
$$

こてで, 関数 $\Phi_{\mathrm{p}}=\Phi_{\mathrm{p}}\left(\mathrm{x}_{0}, \mathrm{y}_{0}\right)$ が

$$
\nabla_{+}^{2} \Phi_{p}=\frac{\partial p^{(2)}}{\partial x}
$$

を満たすものとすれば，（22）の解として 


$$
\begin{aligned}
\hat{\phi}^{(3)=} & -\frac{\mathrm{B}_{0}}{8} \Delta^{\prime \prime \prime}\left(\mathrm{x}^{3}+\mathrm{x}^{2}\right)+\frac{1}{8} \mathrm{~g}_{3}(\mathrm{z})\left(\mathrm{x}^{3}-3 \mathrm{xy}^{2}\right) \\
& -\frac{2 \Delta^{\prime}}{\mathrm{B}_{0}} \Phi_{\mathrm{p}}\left(\mathrm{x}_{0}, \mathrm{y}_{0}\right)
\end{aligned}
$$

とおくことができる。ら ${ }^{(3)}$ 亿関する式を, 磁力線 $(17)$ 亿沿って一周積分するととによって, 容 易に次の式を得るととができる。

$$
\frac{\mathrm{B}_{0}}{\mathrm{~L}}\left[\hat{\zeta}^{(3)}\right]=6 \mathrm{f} \mathrm{p}^{(2)}-4 \mathrm{f} \frac{\partial \Phi}{\partial \mathrm{x}}+\Psi_{\mathrm{ex}}\left(\mathrm{x}_{0}, \mathrm{y}_{0}\right)+\mathrm{const} .
$$

ただし

$$
\begin{aligned}
& f=\frac{1}{B_{0}^{2} L} \int_{0}^{L}\left|\Delta^{\prime}\right|^{2} d z \\
& \Psi_{\mathrm{ex}}\left(\mathrm{x}_{0}, \mathrm{y}_{0}\right)=\mathrm{C}_{0}\left(\mathrm{x}_{0}^{2}+\mathrm{y}_{0}^{2}\right)+\mathrm{C}_{1} \mathrm{x}_{0}+\left(\mathrm{x}_{0}^{2}-\mathrm{y}_{0}^{2}\right), \\
& \mathrm{C}_{0}=\frac{1}{4 \mathrm{LB}_{0}^{2}} \int_{0}^{\mathrm{L}}\left\{2 \mathrm{~B}_{0}^{2}\left|\Delta^{\prime \prime}\right|^{2}+3\left|\mathrm{~b}_{1}^{\prime}\right|^{2}+\left|\mathrm{g}_{2}^{\prime}\right|^{2}\right\} \mathrm{d} z, \\
& \mathrm{C}_{1}=\frac{1}{4 \mathrm{LB}_{0}^{2}} \int_{0}^{\mathrm{L}}\left\{7 \mathrm{~B}_{0}^{2}\left|\Delta \|^{\prime \prime}\right|^{2} \Delta+6 \mathrm{~B}_{0} \mathrm{~g}_{3} \Delta \Delta^{\prime}\right. \\
& +\left(3 b_{1}^{\prime}-g_{2}\right)\left(b_{1}^{\prime}-g_{2}\right) \Delta+2 b_{1} \Delta^{\prime}\left(7 b_{1}^{\prime}-g_{2}\right) \\
& \left.+\left(b_{1}^{\prime}-g_{2}\right) \int_{0}^{z}\left[\frac{2 B_{0}}{R_{0}}+\left(3 b_{1}^{\prime}\left(z^{\prime}\right)-g_{2}\left(z^{\prime}\right)\right) \cdot \Delta^{\prime}\left(z^{\prime}\right)\right] d z^{\prime}\right\} d z, \\
& \mathrm{C}_{2}=\frac{1}{4 \mathrm{~B}_{0}^{2} \mathrm{~L}} \int_{0}^{\mathrm{L}}\left\{3 \mathrm{~B}_{0}^{2}\left|\Delta^{\prime \prime}\right|^{2}+3 \mathrm{~B}_{0} \mathrm{~g}_{3} \Delta^{\prime}-4 \mathrm{~b}_{1}^{\prime} \mathrm{g}_{2}\right\} \mathrm{d} \mathrm{z} \text {. }
\end{aligned}
$$

関数 $\Delta(z)$ を決定する際に, $\Delta(0)$ は全く任意である。それ故 $\mathrm{C}_{1}=0$ となるように $\Delta(0)$ を 選ぶしとが許される。さて, 次のような量

$$
\Psi=\Psi_{\mathrm{ex}}-4 \mathrm{f} \frac{\partial \Phi_{\mathrm{p}}}{\partial \mathrm{x}}
$$

を導入すると, $\mathrm{p}^{(2)}=\mathrm{p}^{(2)}(\Psi)$ であるから，(31)を（23）と連立させて解けば，プラズマの 等圧面 $\Psi$ の形を决定するととができる。（31）の両辺に $\nabla_{+}^{2}$ を作用させて，（23）を考虑すると， $\Phi_{\mathrm{p}}^{(2)}$ を含まない単一の偏徽分方程式 


$$
\nabla_{\perp}^{2} \Psi=2 \mathrm{C}_{0}-4 \mathrm{f} \frac{\partial^{2} \mathrm{p}^{(2)}(\Psi)}{\partial \mathrm{x}^{2}}
$$

を得る。式(32)において,パラメータ

$$
\beta_{*}=-4 \mathrm{f} \frac{\mathrm{dp}}{\mathrm{d} \Psi}
$$

の值が重要な役割をもつ。 $\beta_{*}<1$ の領域においては，(32）は棈円型の方程式であるが， $\beta_{*}>$ 1 の領域があると, その領域では（32）は双曲型の方程式になる。方程式 (32) が混合型の方程 式になりうるというととは，極めて複雑な状況を生み出すが，方程式の解がなくなるとか，解を 求められないとかいうととを意味してはいない。との状況は, 元の方程式 (31) と（23）を連立 させて解くことにすれば，見かけ上はなくなる。

\section{§ 4. 安定性の考察}

エネルギー原理を用いて，プラズマの安定性についての一般的な考察を行う。その際に，プラ ズマの変位 $\xi$ に対しても, 平衡量と同様に (1)のオーダリングが仮定できるものとする。

エネルギー積分は，プラズマ流体からの寄与 $\delta \mathrm{W}_{\mathrm{F}}$ ，真空領域からの寄与 $\delta \mathrm{W}_{\mathrm{V}}$ ，プラズマ表 面からの寄与 $\delta \mathrm{W}_{\mathrm{S}}$ の三つの部分に分けられる。

$$
\delta \mathrm{W}=\delta \mathrm{W}_{\mathrm{F}}+\delta \mathrm{W}_{\mathrm{S}}+\delta \mathrm{W}_{\mathrm{V}}
$$

（1）のオーダリングに基づいて $\delta \mathrm{W}$ を展開する前に, 若干の変形を加えておくのが好都合であ

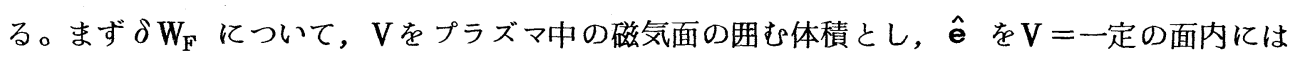
ない任意のべクトルとするとき，

$$
\begin{array}{r}
\delta \mathrm{W}_{\mathrm{F}}=\int_{\mathrm{V}_{\mathrm{F}}}\left\{\left|\mathrm{Q}+\frac{\mathrm{J} \times \mathbf{e}}{\mathbf{e} \cdot \nabla \mathrm{V}} \xi_{\mathrm{V}}\right|^{2}+\gamma \mathrm{p}(\operatorname{div} \xi)^{2}\right. \\
\left.-\mathrm{K} \xi_{\mathrm{V}}^{2}\right\} \mathrm{d} z,
\end{array}
$$

と書ける。たぶし $\xi_{\mathrm{V}}=\xi \cdot \nabla \mathrm{V}, \mathrm{Q}=\mathrm{curl}(\boldsymbol{\xi} \times \mathrm{B})$ ，

$$
\mathrm{K}=\frac{1}{(\hat{\mathbf{e}} \cdot \nabla \mathrm{V})^{2}} \mathrm{~J} \times \hat{\mathbf{e}}[\mathrm{B} \cdot \boldsymbol{\nabla} \hat{\mathbf{e}}-\hat{\mathbf{e}} \cdot \nabla \mathrm{B}+\mathrm{J} \times \hat{\mathbf{e}}]
$$

である。こてで， 


\section{蛇行するバンピー・トーラスの平衡と安定性}

$$
\mathrm{J}=\dot{\mathrm{p}}\left\{\nabla \hat{\zeta}+\frac{\nabla z}{\mathrm{~T}}\right\} \times \nabla \mathrm{V}, \quad \dot{\mathrm{p}} \equiv \frac{\mathrm{d} \mathrm{p}}{\mathrm{dV}}
$$

の関係を用い, $\mathrm{B} \cdot \boldsymbol{\nabla} \mathrm{V}=0, \mathrm{~B} \cdot \boldsymbol{\nabla} \hat{\zeta}+\frac{1}{\mathrm{~T}} \mathrm{~B} \cdot \boldsymbol{\nabla} \mathrm{z}=1$ を考虑すると

$$
\begin{aligned}
\mathrm{K}= & -\mathrm{B} \cdot \nabla\left\{\frac{\dot{\mathrm{p}}}{\hat{\mathrm{e}} \cdot \nabla \mathrm{V}}\left(\hat{\mathrm{e}} \cdot \nabla \hat{\zeta}+\frac{1}{\mathrm{~T}} \hat{\mathbf{e}} \cdot \nabla z\right)\right\} \\
& +\frac{1}{(\hat{\mathrm{e}} \cdot \nabla \mathrm{V})^{2}}|\mathrm{~J} \times \hat{\mathrm{e}}|^{2}-\frac{\dot{\mathrm{p}}}{\mathrm{T}^{3}} \frac{\hat{\mathrm{e}} \cdot \nabla z}{\hat{\mathrm{e}} \cdot \nabla \mathrm{V}}(\mathrm{B} \cdot \nabla \mathrm{T})
\end{aligned}
$$

と書けるから，ての第一項を含む部分を一度部分積分を行うと， $\delta \mathrm{W}_{\mathrm{F}}$ を次の形に書くことがで きる。

$$
\begin{aligned}
& \delta \mathrm{W}_{\mathrm{F}}=\int_{\mathrm{V}_{\mathrm{F}}}\left\{|\widetilde{\mathbf{Q}}|^{2}+\gamma \mathrm{p}(\operatorname{div} \xi)^{2}-\mathrm{K}_{2} \xi_{\mathrm{V}}^{2}\right\} \mathrm{d} \tau \\
& +\iint_{V_{F}} \xi_{\mathrm{V}}^{2} \dot{\mathrm{p}}(\mathrm{B} \cdot \boldsymbol{\nabla} z) \frac{\mathrm{d}}{\mathrm{d} \mathrm{V}}[\hat{\zeta}] \mathrm{dx}_{0} \mathrm{~d} \mathrm{y}_{0} . \\
& \widetilde{\mathrm{Q}}=\mathrm{Q}-\dot{\mathrm{p}} \xi_{\mathrm{v}}\left(\boldsymbol{\nabla} \hat{\zeta}+\frac{1}{\mathrm{~T}} \boldsymbol{\nabla} z\right), \\
& \mathrm{K}_{2}=\dot{\mathrm{p}}^{2}\left\{\left|\nabla \hat{\zeta}+\frac{1}{\mathrm{~T}} \nabla \mathrm{z}\right|^{2}-\frac{1}{\mathrm{~T}^{3}} \mathrm{~B} \cdot \nabla \mathrm{z}\right\}
\end{aligned}
$$

次に，真空領域の寄与 $\delta \mathrm{W}_{\mathrm{v}}$ を考えよう。真空領域での磁場の変化を $\delta \mathrm{B}_{\mathrm{V}}$ と書くと，

$$
\delta \mathrm{W}_{\mathrm{V}}=\int_{\mathrm{V}_{\mathrm{V}}}\left|\delta \mathrm{B}_{\mathrm{v}}\right|^{2} \mathrm{~d} \tau .
$$

こてでは, 真空磁場をスカラー・ポテンシャルメを用いて

$$
\delta \mathrm{B}_{\mathrm{v}}=\nabla x, \quad \nabla^{2} x=0
$$

とあらわすのが便利である。スカラーポテンシャルを用いたときの，プラズマ表面での境界条件 は,

$$
\begin{aligned}
\frac{\partial x}{\partial \mathrm{n}} & =\operatorname{Div}\left(\xi_{\mathrm{n}} \mathrm{B}_{\mathrm{v}}\right) \\
& \equiv \mathrm{B}_{\mathrm{v}} \cdot \boldsymbol{\nabla} \xi_{\mathrm{n}}-\xi_{\mathrm{n}} \mathbf{n}(\mathbf{n} \cdot \boldsymbol{\nabla}) \mathrm{B}_{\mathrm{v}} \cdot
\end{aligned}
$$

とてでDiv は表面 $\mathrm{S}$ 上での発散を表わし， $\xi_{\mathrm{n}}$ は $\xi$ の法線方向の成分を表わす。 $x$ は一般に多価 
関数で, トーラスをトロイダル方向とポロイダル方向に一周した時の周期をそれぞれ $\Gamma_{1} ， \Gamma_{2}$ とするとき，

$$
x=x_{*}+\Gamma_{1} \theta_{1}+\Gamma_{2} \theta_{2}
$$

と書くてとができる。こてで ${ }_{*}$ は $\mathrm{V}_{\mathrm{V}}$ において一価な関数，また $\theta_{1} ， \theta_{2}$ は $\mathrm{V}_{\mathrm{V}}$ において $\nabla^{2} \theta_{\mathrm{i}}=0, \mathrm{~V}_{\mathrm{V}}$ の境界面上で $\partial \theta_{\mathrm{i}} / \partial \mathrm{n}=0$ をみたし, かつ, $\theta_{1}\left(\theta_{2}\right)$ のトロイダル (ポロイダル ) 周期が 1 ，ポロイダル（トロイダル）周期が 0 であるような関数である。

インダクタンス行列

$$
\mathrm{L}_{\mathrm{ik}}=\int_{\mathrm{V}_{\mathrm{V}}}\left(\boldsymbol{\nabla} \theta_{\mathrm{i}} \cdot \nabla \theta_{\mathrm{j}}\right) \mathrm{d} \tau
$$

の逆行列 $\mathrm{L}^{-1} \mathrm{ik}$ を用いると

$$
\begin{aligned}
\delta \mathrm{W}_{\mathrm{v}} & =\int_{\mathrm{V}_{\mathrm{v}}}\left|\nabla x_{*}\right|^{2} \mathrm{~d} \tau \\
& +\sum_{\mathrm{i}=1}^{2} \sum_{\mathrm{k}=1}^{2} \mathrm{~L}^{-1}{ }_{\mathrm{ik}} \oint_{\mathrm{S}} \xi_{\mathrm{n}} \mathrm{B}_{\mathrm{v}} \cdot \nabla \theta_{\mathrm{i}} \mathrm{dS} \oint_{\mathrm{S}} \xi_{\mathrm{n}} \mathrm{B}_{\mathrm{v}} \cdot \nabla \theta_{\mathrm{k}} \mathrm{dS} .
\end{aligned}
$$

と書くととができる ${ }^{[8]}$ 。カララー・ポテンシャルの多価性を考慮に入れた第二項は常に正であ り, 安定化の方向に働らく。前節で仮定したような鏡像対称性をもつ系においては $\nabla \theta_{1}$ は B と 同じ対称性をもち， $\boldsymbol{\nabla} \theta_{2}$ は $\mathrm{J}$ と同じ対称性をもつ。乙のとき, インダクタンス行列の非対角成 分は 0 となり，また， $\xi_{\mathrm{n}}$ が同様の鏡像対称性をもたなければ $(38)$ の第二項は 0 になる。以下 ではての項を無視して考える。

$\delta \mathrm{W}_{\mathrm{S}}$ については, プラズマの圧力 $\mathrm{p}$ が表面で連続的に0になり, 表面電流がないときには恒 等的に0になる。

（1）のオーダリングに基づいて

$$
\begin{aligned}
& \xi=\xi^{(0)}+\varepsilon \xi^{(1)}+\cdots \cdots, \\
& \delta \mathrm{W}=\delta \mathrm{W}^{(0)}+\varepsilon \delta \mathrm{W}^{(1)}+\varepsilon^{2} \delta \mathrm{W}^{(2)}+\cdots \\
& x=\chi^{(0)}+\varepsilon x^{(1)}+\varepsilon^{2} x^{(2)}+\cdots
\end{aligned}
$$

と展開すると， $\delta \mathrm{W}$ 亿負の寄与を与えうる項は $\delta \mathrm{W}_{\mathrm{F}}$ の中の $\mathrm{K}_{2}$ を含む項と $(34)$ の第二項であ り，てれらはいずれも $\varepsilon^{6}$ のオーダーである。それ以外の項は全て二乗の和の形をしているから， 
$\varepsilon^{6}$ より低次の項は全て0でなければならない。こうして

$$
\begin{aligned}
& \widetilde{Q}^{(0)}=\widetilde{Q}^{(1)}=\widetilde{Q}^{(2)}=0, \\
& \nabla_{+} \xi^{(0)}=\nabla \cdot \xi_{+}^{(1)}=0, \\
& x_{*}^{(0)}=x_{*}^{(1)}=x_{*}^{(2)}=0 . \\
& \xi^{(0)}=\frac{1}{\mathrm{~B}} \mathrm{e}_{z} \times \boldsymbol{\nabla}^{(0)}\left(\mathrm{x}_{0}, \mathrm{y}_{0}\right), \quad \xi_{\mathrm{z}}^{(1)}=\Delta^{\prime} \xi_{\mathrm{X}}^{(0)},
\end{aligned}
$$

を得る。 $\varepsilon^{6}$ のオーダーで, 磁力線の関数 $\mathrm{X}\left(\mathrm{x}_{0}, \mathrm{y}_{0}\right), \mathrm{Y}\left(\mathrm{x}_{0}, \mathrm{y}_{0}\right), \mathrm{Z}\left(\mathrm{x}_{0}, \mathrm{y}_{0}\right)$ を

$$
\begin{aligned}
& \mathrm{X}=\frac{2}{\mathrm{~B}_{0}} \dot{\mathrm{p}} \xi_{\mathrm{V}}^{(0)}, \\
& \mathrm{Q}^{(3)}=\frac{1}{\mathrm{~B}_{0}} \xi_{\mathrm{V}}^{(0)} \dot{\mathrm{p}}\left(\varepsilon_{\mathrm{Z}}+\Delta^{\prime} \mathbf{e}_{\mathrm{X}}\right)+\Delta^{\prime} \mathbf{e}_{\mathrm{Z}} \times \nabla \mathrm{Y} \\
& \nabla x_{*}^{(3)}=\Delta^{\prime} \mathbf{e}_{\mathrm{Z}} \times \nabla \mathrm{Z}
\end{aligned}
$$

によって導入すると，

$$
\begin{aligned}
& \delta \mathrm{W}^{(6)}= \delta \mathrm{W}_{*} \oint\left|\Delta^{\prime}\right|^{2} \mathrm{dz} \\
& \delta \mathrm{W}_{*}=\iint_{\mathrm{V}_{\mathrm{F}}}\left\{\left|\frac{\partial \mathrm{Y}}{\partial \mathrm{x}_{0}}\right|^{2}+\left|\frac{\partial \mathrm{Y}}{\partial \mathrm{y}_{0}}-\mathrm{X}\right|^{2}-\frac{1}{\beta *} \mathrm{X}^{2}\right\} \mathrm{d} \mathrm{x}_{0} \mathrm{~d} \mathrm{y_{0 }} \\
& \quad+\iint_{\mathrm{V}_{\mathrm{V}}}\left\{\left|\frac{\partial \mathrm{Z}}{\partial \mathrm{x}_{0}}\right|^{2}+\left|\frac{\partial \mathrm{Z}}{\partial \mathrm{y}_{0}}\right|^{2}\right\} \mathrm{dx}_{0} \mathrm{~d} \mathrm{y}_{0}
\end{aligned}
$$

を得る。プラズマ表面上の境界条件は

$$
\mathrm{Z}=\mathrm{Y}
$$

また，領域 $\mathrm{V}_{\mathrm{V}}$ を囲む外部導体上では

$$
Z=0
$$

となる。（41）において, $\mathrm{Y} \equiv \mathrm{Z} \equiv 0$ とおくと, 安定性の必要条件として,

$$
1 / \beta_{*}<1
$$


を得る。てのとき $\mathrm{Q} / / \mathrm{B}$ であるから，ての条件は，一般化された交換不安定性，あるいはフルー ト・モードに対する条件に他ならない。実際に，条件 $(42)$ は,

$$
\frac{\mathrm{d}}{\mathrm{dp}}\left(\oint \frac{\mathrm{d} \mathrm{l}}{\mathrm{B}} \oint \mathrm{Bd} \mathrm{l}\right)>0
$$

と同等であるてとが容易に確かめられる。（41）において, 局在化した不安定性に対する条件も 導くことができる。いま，y方向の波長が $\mathrm{x}$ 方向の波長にくらべて十分小さいと仮定して，y 方 向の座標を $\eta=\mathrm{y}_{0} / \varepsilon^{\prime}$ によってひき伸ばし，

$$
\mathrm{X}=\mathrm{X}^{(0)}\left(\mathrm{x}_{0}, \eta\right)+\cdots \cdot, \quad \mathrm{Y}=\varepsilon^{\prime} \mathrm{Y}^{(1)}\left(\mathrm{x}_{0}, \eta\right)+\cdots \cdots
$$

とおくと，

$$
\delta \mathrm{W}_{*}^{(0)}=\varepsilon^{\prime} \int\left\{\left|\frac{\partial \mathrm{Y}^{(1)}}{\partial \eta}+\mathrm{X}^{(0)}\right|^{2}-\frac{1}{\beta *}\left|\mathrm{X}^{(0)}\right|^{2}\right\} \mathrm{dx}_{0} \mathrm{~d} \eta
$$

となり，

$$
1 / \beta_{*}<0
$$

という条件を得る。乙の条件は,メルシェの条件と同じ種類の条件である。（磁力線によって織 りなられた「磁気面」の存在しない場合には，局在化したモードは，必らずしも一つの「磁気面」 の近傍に局在化するとは限らないということに注意すべきである。）ての局在化したモードに対 する必要条件は, 决して満足させることはできない。しかし，てのような局在化したモードは， 実際のプラズマ中では，ラーモア半径の有限性などの諸効果のために存在しないだろうから，よ り波長の長いモードを考える必要がある。そのためには，平衡の具体的な形が必要になる。

\section{§5. 圧力が $\Psi$ の線形関数のときの平衡解}

ての節では, 圧力 $\mathrm{p} か ゙ ， \Psi の$ 線形の関数として

$$
\mathrm{p}(\Psi)= \begin{cases}\mathrm{p}_{0}\left(1-\Psi / \Psi_{0}\right), & \left(\Psi<\Psi_{0}\right. \text { のとき), } \\ 0 & \left(\Psi>\Psi_{0}\right. \text { のとき), }\end{cases}
$$

で与えられる場合の解析解を求め，その性質を議論するととにする。このとき， $\beta *$ は定数

$$
\beta_{*}=4 \mathrm{f} \quad \mathrm{p}_{0} / \Psi_{0}
$$




\section{蛇行するバンピー・トーラスの平衡と安定性}

であり, 方程式 (31) は,

$$
\begin{array}{ll}
\left(1-\beta_{*}\right) \frac{\partial^{2} \Psi_{\mathrm{i}}}{\partial \mathrm{x}_{0}^{2}}+\frac{\partial^{2} \Psi_{\mathrm{i}}}{\partial \mathrm{y}_{0}^{2}}=2 \mathrm{C}_{0}, & \left(\Psi<\Psi_{0}\right) \\
\frac{\partial^{2} \Psi_{\mathrm{e}}}{\partial \mathrm{x}_{0}^{2}}+\frac{\partial^{2} \Psi_{\mathrm{e}}}{\partial \mathrm{y}_{0}^{2}}=2 \mathrm{C}_{0} & \left(\Psi>\Psi_{0}\right)
\end{array}
$$

境界条件は, $\mathrm{x}_{0}^{2}+\mathrm{y}_{0}^{2} \rightarrow \infty$ とき

$$
\Psi_{\mathrm{e}}-\mathrm{C}_{0}\left(\mathrm{x}_{0}^{2}+\mathrm{y}_{0}^{2}\right)-\mathrm{C}_{2}\left(\mathrm{x}_{0}^{2}-\mathrm{y}_{0}^{2}\right) \rightarrow 0,
$$

プラズマ表面上での境界条件としては

$$
\begin{aligned}
& \Psi_{\mathrm{i}}=\Psi_{\mathrm{e}}=\Psi_{0}, \\
& \mathrm{n}_{\mathrm{x}}\left(1-\beta_{*}\right) \frac{\partial \Psi_{\mathrm{i}}}{\partial \mathrm{x}_{0}}+\mathrm{n}_{\mathrm{y}} \frac{\partial \Psi_{\mathrm{i}}}{\partial \mathrm{y}_{0}}=\mathrm{n}_{\mathrm{x}} \frac{\partial \Psi_{\mathrm{e}}}{\partial \mathrm{x}_{0}}+\mathrm{n}_{\mathrm{y}} \frac{\partial \Psi_{\mathrm{e}}}{\partial \mathrm{y}_{0}},
\end{aligned}
$$

たぐし， $\mathrm{n}_{\mathrm{x}}, \mathrm{n}_{\mathrm{y}}$ はプラズマ表面の法線ベクトルの成分をあらわすものとする。

プラズマの断面が棈円形をしていると予想して，

$$
\Psi_{\mathrm{i}}=\frac{\Psi_{0}}{\mathrm{a}^{2}}\left(\mathrm{e} \mathrm{x}_{0}^{2}+\frac{\mathrm{y}_{0}^{2}}{\mathrm{e}}\right),
$$

とおく。実際の計算を行うには，菁円座標 $(\mathrm{u}, \mathrm{v})$ を

$$
\mathrm{x}_{0}=\frac{\mathrm{a}}{\sqrt{1-\sigma^{2}}}\left(\mathrm{u}+\frac{\sigma}{\mathrm{u}}\right) \cos \mathrm{v}, \quad \mathrm{y}_{0}=\frac{\mathrm{a}}{\sqrt{1-\sigma^{2}}}\left(\mathrm{u}-\frac{\sigma}{\mathrm{u}}\right) \sin \mathrm{v},
$$

によって導入し， $\mathrm{u}=1$ がプラズマの表面を表わすものとする。 $\mathrm{e}$ は断面の $\mathrm{y}$ 軸と $\mathrm{x}$ 軸の比をあ らわし，

$$
\sigma=\frac{1-\mathrm{e}}{1+\mathrm{e}}, \quad \mathrm{e}=\frac{1-\sigma}{1+\sigma},
$$

の関係がある。計算の結果，次の関係を得る。

$$
\begin{aligned}
& \beta_{*}=\frac{(\mathrm{e}+1)^{2}\left[\mathrm{C}_{0}\left(\mathrm{e}^{2}-1\right)+\mathrm{C}_{2}\left(\mathrm{e}^{2}+1\right)\right]}{\mathrm{e}^{2}\left[\mathrm{C}_{0}\left(\mathrm{e}^{2}+2 \mathrm{e}-1\right)+\mathrm{C}_{2}(\mathrm{e}+1)^{2}\right]}, \\
& \bar{\beta} \equiv \frac{\mathrm{p}_{0}}{\mathrm{~B}_{0}^{2}}=\frac{\mathrm{a}^{2}}{8 \mathrm{fB}_{0}^{2}} \frac{(\mathrm{e}+1)^{2}}{\mathrm{e}^{2}}\left[\mathrm{C}_{0}\left(\mathrm{e}^{2}-1\right)+\mathrm{C}_{2}\left(\mathrm{e}^{2}+1\right)\right] .
\end{aligned}
$$

$\mathrm{p}_{0}>0$ であるという条件から 


$$
\left(\mathrm{C}_{0}+\mathrm{C}_{2}\right) \mathrm{e}^{2}>\mathrm{C}_{0}-\mathrm{C}_{2}
$$

いま, $\mathrm{C}_{0}>\mathrm{C}_{2}>0$ とすると，

$$
\mathrm{e}_{\mathrm{V}}=\left(\frac{\mathrm{C}_{0}-\mathrm{C}_{2}}{\mathrm{C}_{0}+\mathrm{C}_{2}}\right)^{1 / 2}
$$

は, 真空磁場のつくる楕円形の $\oint \mathrm{d} \ell / \mathrm{B}$ 面の楕円度であるから, 関係式 (48) は, プラズマが あるときの $\oint \mathrm{d} \ell / \mathrm{B}$ 面の断面は，圧力が大きくなる程， $\mathrm{y}$ 方向にのびるてとを意味している。 このとき， $\mathrm{p}_{0}$ が増すにつれて $\beta_{*}$ は增し，

$$
\mathrm{e}=\mathrm{e}_{\mathrm{v}}^{2}+\sqrt{\mathrm{e}_{\mathrm{v}}^{4}+\mathrm{e}_{\mathrm{v}}^{2}}
$$

のとてろで $\beta_{*}=1$ を越え, 更に $\mathrm{p}_{0}$ が増すと $\beta_{*}$ は減少して，1亿漸近する。

$\mathrm{C}_{2}>\mathrm{C}_{0}>0$ のとき, 真空磁場のつくる $\oint \mathrm{d} \ell / \mathrm{B}=$ 一定の面は閉じた面を形成していない が,

$$
\bar{\beta} \geq \frac{\mathrm{a}^{2}}{8 \mathrm{fB}_{0}^{2}}\left\{\left(\mathrm{C}_{0}+\mathrm{C}_{2}\right)^{1 / 3}+\left(\mathrm{C}_{2}-\mathrm{C}_{0}\right)^{1 / 3}\right\}^{3}
$$

のとき,プラズマの影響によって，閉じた「磁気面」が形成される。とのとき， $\beta_{*}>1$ であり， 一つの $\bar{\beta}$ の值に対して, 二つの異なる棈円度 $\mathrm{e} と \beta_{*}$ をもつ平衡が存在しうる。

種々の $\left(\mathrm{C}_{0}-\mathrm{C}_{2}\right) /\left(\mathrm{C}_{0}+\mathrm{C}_{2}\right)$ の值に対し, $\beta_{*}, \bar{\beta}$ と $\mathrm{e}$ と関係を図1, 2 亿示す。 この平衡解に対する, $\mathrm{m}=1$ モードの不安定性の成長率は, 次のようにして計算できる。 $\delta \mathrm{W}$

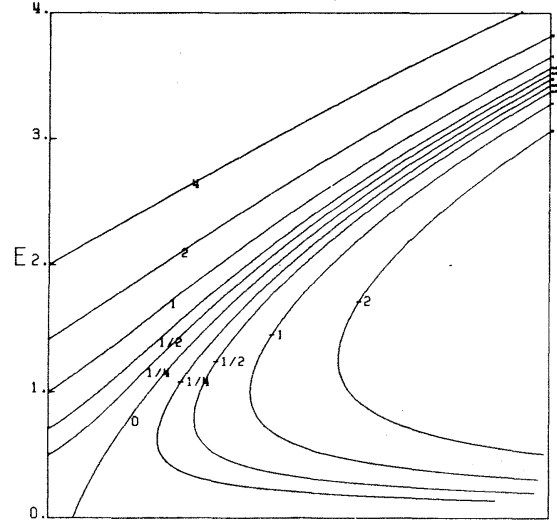

BETA

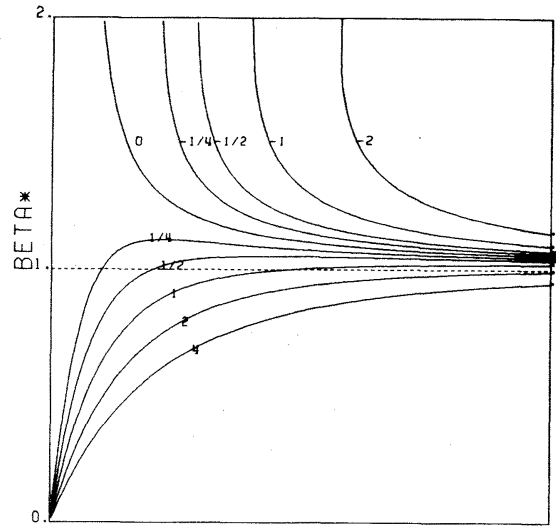

BETA

図2 $\beta_{*}-\bar{\beta}$ 
を最小化する時の規格化条件として $\int \rho|\xi|^{2} \mathrm{~d} \tau=1$ のかわりに, $\int|\mathrm{X}|^{2} \mathrm{~d} \tau=1$ を用 いると, 固有值方程式として, 領域 $V_{F}$ では,

$$
\begin{aligned}
& \left(\lambda-1+\frac{1}{\beta_{*}}\right) \mathrm{X}+\frac{\partial \mathrm{Y}}{\partial \mathrm{y}_{0}}=\mathrm{F}(\mathrm{V}), \\
& \nabla_{+}^{2} \mathrm{Y}=\frac{\partial \mathrm{X}}{\partial \mathrm{y}},
\end{aligned}
$$

領域 $\mathrm{V}_{\mathrm{V}}$ において

$$
\nabla_{\perp}^{2} Z=0
$$

また， $\mathrm{V}_{\mathrm{F}}$ と $\mathrm{V}_{\mathrm{V}}$ の境界面 $\mathrm{S}$ の上で

$$
\frac{\partial \mathrm{Y}}{\partial \mathrm{u}}-\frac{\mathrm{a}}{\sqrt{\mathrm{e}}} \sin \mathrm{v} \mathrm{X}=\frac{\partial \mathrm{Z}}{\partial \mathrm{u}}
$$

をうる。今, プラズマを井む真空領域 $\mathrm{V}_{\mathrm{V}}$ は， $\mathrm{u}=\mathrm{w}(\gg 1)$ におかれた, プラズマの断面と 共焦な楕円形の完全導体壁によって制限されていると仮定する。すると，

$$
\mathrm{X}_{1_{\mathrm{H}}}=\mathrm{x}, \quad \mathrm{X}_{1 \mathrm{~V}}=\mathrm{y}
$$

なる変位に対して，次のような固有值を得ることができる。

$$
\begin{aligned}
& \lambda_{1 \mathrm{H}}=1-\frac{1}{(\mathrm{e}+1)^{2}}-\frac{1}{\beta_{*}}+\frac{4 \mathrm{e}}{(\mathrm{e}+1)^{4}} \frac{1}{\mathrm{w}^{4}}, \\
& \lambda_{1 \mathrm{~V}}=\frac{\mathrm{e}^{2}}{(\mathrm{e}+1)^{2}}-\frac{1}{\beta_{*}}+\frac{4 \mathrm{e}^{3}}{(\mathrm{e}+1)^{4}} \frac{1}{\mathrm{w}^{4}}
\end{aligned}
$$

これから,リッッの原理によって, 成長率 $\gamma$ を計算すると, $\beta *$ に対する平衡の関係式を用いて,

$$
\left(r_{ \pm} \mathrm{a} / \mathrm{v}_{\mathrm{A}}\right)^{2}=\bar{\beta} \mathrm{a}^{2}\left(\mathrm{C}_{0} \pm \mathrm{C}_{2}\right)-\frac{16 \mathrm{e}^{2}}{(\mathrm{e}+1)^{4}} \frac{\bar{\beta}^{2}}{\mathrm{w}^{4}} \frac{1}{\mathrm{~L}} \int_{0}^{\mathrm{L}}\left|\Delta^{\prime}\right|^{2} \mathrm{~d} z
$$

をうる。乙てで十符号は垂直方向の変位に対するもので，一符号は水平方向の変位に対するもの である。なお，乙とで求めた成長率 $\gamma$ は, 密度が $\mathrm{p}$ と同じ $\Psi$ 依存性をもつ場合には，正しい固有 值となっている。（55）をMiller による鋭いプラズマ境界をもつ円形断面ピンチの計算 $[5]$ と 比較すると， $\beta \ll 1$ のをき似た形になっていて矛盾してはいない。 
$\S 6$. 結 論

前節の安定性の計算は， $\ell= \pm 1$ の系においては, 交換不安定性（フルート・モード）は安定 化されうるが，磁力線の形をかえるような，低两の不安定性が存在するとと，ての不安定性に対 して, 導体壁を十分プラズマの近くにおけば安定化されうるととを示している。一般的には，水 平方向への不安定性は磁場配位を適当に選ぶことによって導体壁に依らずに安定化できる。しか し, 垂直方向の不安定性は, 導体壁をプラズマ表面に密着させても, 安定化することはできない。 この結果は，MB T実験でのセクター・プラズマの見かけ上の安定性を説明しない。 前節までの計算において，次の上うな一般化が容易に可能である。（24）の右辺に，外部磁場 として る。てのとき，プラズマの断面にもはや棈円ではなくなり，平衡解は数值的にしか求められなく なる。また，プラズマの位置は $\beta$ の值によって変わる。プラズマの断面が三角形の成分をもつて とが，安定性にどのような影響を与えるかは十分興味ある問題である。

\section{REFERENCES}

1) J. Todoroki, Plasma Physics, 18 (1976) 137.

2) J. Todoroki, J. Phys. Soc. Japan, 45 (1978) 635.

3) J. Todoroki et al., Plasma Physics and Controlled Nuclear Fusion Research 1976 (IAEA, Vienna, 1977) vol. 2, p. 215.

4) R. L. Morse, W. B. Riesenfeld and J. L. Johnson, Plasma Phys., 10 (1968) 543.

5) G. Miller, Phys. of Fluids, 20 (1977) 928.

6) H. Grad, Phys. of Fluids, 10 (1967) 137.

7) H. Grad, Plasma Physics and Controlled Nuclear Fusion Research 1971 (IAEA, Vienna, 1971) vol. 2, p. 229.

8) R. V. Lüst and E. Martensen, Z. Naturforsch, A I5 (1960) 706. 